\title{
POSITIVE YOUTH DEVELOPMENT PERSPECTIVE: THE INTERPLAY BETWEEN THE 5CS AND ANXIETY
}

\author{
Ana Kozina ${ }^{1}$, Nora Wiium ${ }^{2}$, \& Tina Pivec ${ }^{1}$ \\ ${ }^{1}$ Educational Research Institute (Slovenia) \\ ${ }^{2}$ Bergen University (Norway)
}

\begin{abstract}
Anxiety is one of the most frequent psychological difficulties in childhood and adolescence (Neil \& Christensen, 2009), and is related to numerous short- and long-term negative outcomes (Kozina, 2013; Twenge, 2000). A large body of evidence consistently shows that the 5Cs of Positive Youth Development (PYD) are positively related to adolescents' contribution to self, family and society as well as negatively related to risky behaviors and emotional difficulties, such as anxiety and depression (Lerner, et al, 2013). The 5Cs represent competencies, such as competence (a sense of positive self-worth and self-efficacy), confidence (positive view of one's actions in specific domains), connection (positive reciprocal bonds an adolescent has with people and institutions), character (possession of standards for correct behavior with respect to societal and cultural norms) and caring (sense of sympathy and empathy for others) (Lerner, 2007). In the present paper, we investigate the relationship between the 5Cs and anxiety in a Slovenian youth sample $\left(N=195, M_{\text {age }}=17.10\right.$ years), by using PYD questionnaire (Geldof et al., 2013) and AN-UD anxiety scale (Kozina, 2012). The PYD perspective (Lerner 2007) is used for the first time as a framework for an in-depth understanding of the 5Cs and anxiety among adolescents in Slovenia. The findings show negative associations between anxiety and the PYD dimensions of competence, confidence, connection and character. The strongest correlations were observed with confidence and connection. However, a positive association was observed between anxiety (and its components) and caring. The findings are informative for intervention within an educational framework targeting the 5Cs with the aim of decreasing risky behaviors and emotional difficulties. Still, extra care would have to be taken in the promotion of caring in anxious students. In that matter, the paper raises the question of what could be considered as optimal levels of caring in anxiety intervention and prevention.
\end{abstract}

Keywords: Positive youth development, anxiety, Slovenia.

\section{Introduction}

Anxiety is by definition a combination of cognitive (e.g., worries), physiological (e.g., nausea), emotional (e.g. fear) and behavioral responses (e.g., avoidance) (Silverman and Treffers, 2001). Even though anxiety is common throughout the lifespan and a part of everyday life, it becomes problematic when it is persistent, frequent and severe enough to restrain an individual in their everyday functioning (Weems \& Stickle, 2005). Difficulties related to anxiety are common in childhood and adolescence (Neil \& Christensen, 2009) and are related to numerous short- and long-term negative outcomes. High levels of anxiety interfere significantly with children's and adolescents' adaptive functioning, social competence and social adjustment (Last, Hansen, \& Franco, 1997; Schwartz, Hopmeyer, Gorman, Nakamoto, \& McKay, 2006), and when present in childhood they may follow a chronic course (Ialongo, Edelsohn, Werthamer-Larsson, Crockett \& Kellam, 1996; Woodworth \& Fergusson, 2001). There is a documented increase in anxiety in Slovenia (Kozina, 2014) and abroad (Twenge, 2000) thus, indicating a need for prevention and intervention. A large body of evidence consistently shows that the 5Cs of PYD (competence, caring, confidence, connection and character) are positively related to adolescents' contribution to self, family and society as well as negatively related to risky behaviors and emotional difficulties, such as anxiety and depression and therefore show potential to be used as a prevention model (Lerner, et al, 2013). Positive youth development (PYD) is embedded in the relational development systems model (Overton, 2015) that emphasizes the potential of the individual to contribute to the development of self and the society (Lerner, 2007). Core elements of PYD are the 5Cs of competence (a sense of positive self-worth and self-efficacy), confidence (positive view of one's actions in specific 
domains), connection (positive reciprocal bonds an adolescent has with people and institutions), character (possession of standards for correct behavior with respect to societal and cultural norms) and caring (sense of sympathy and empathy for others) (Lerner, 2007).

In the present study, we first examined associations between anxiety and PYD outcomes, such as character, confidence, connection, and caring in a convenience sample of adolescents in Slovenia and second, we analyzed the predictive power of the 5Cs for anxiety and its components. The focus on the anxiety components is especially important due to the multidimensional nature of anxiety. Since the different components of anxiety in childhood lead to different problems in adolescence and adulthood (Olatunji \& Cole, 2009), a multidimensional evaluation of anxiety is crucial when planning an intervention.

\section{Methods}

In this study, we used a convenience sample of Slovene adolescents $(N=449,312$ females and 130 males) aged between 15 and $23\left(M_{\mathrm{age}}=17.10\right.$ years $)$ enrolled in upper secondary schools. Data collection took place in 2017. We measured anxiety and the 5Cs of PYD using: PYD questionnaire (Geldhof et al., 2013) and AN-UD anxiety scale (Kozina, 2012)

The PYD questionnaire (Geldof et al., 2013) consists of 34 items answered on a 5-point Likert scale (with responses ranging from $1=$ strongly disagree to $5=$ strongly agree). The items measure the 5Cs: competence (e.g., "I do very well in my class work at school"), confidence (e.g., "All in all, I am glad I am me"), caring (e.g., "When I see another person who is hurt or upset, I feel sorry for them"), Character (e.g., "I hardly ever do things I know I shouldn't do"), and connection (e.g., "My friends care about me"). The questionnaire has proven to be psychometrically adequate in the sample used in this study with reliability coefficients as follows: .78 (competence); .82 (confidence); 74 (character); .91 (caring); .81 (connection). CFA (Confirmatory Factor Analyses) on the present data confirmed a good fit of the 5-factor structure: X2 $(517)=8745.158, \mathrm{p}<.001$, RMSEA $=.063$, $90 \%$ CI [.062 - .065], CFI $=.947$; TLI $=.942$ (Gonzalez, Kozina, \& Wiium, 2017).

AN-UD anxiety scale (Kozina, 2012) measures general anxiety and three anxiety components with 14 self-report items: emotions - eight items (e.g., I suddenly feel scared and I don't know why.), worries - three items (e.g., I am very worried about my marks.) and decisions - three items (e.g., I have difficulties making decisions.). On the scale, students indicate the frequency ( $1=$ Never, $2=$ Rarely, $3=$ Sometimes, $4=$ Often, 5 = Always). The component scores can be summed up into an overall anxiety score. The three-factor structure was confirmed with a confirmatory factor analysis (CFA) on samples of primary/lower-secondary students (RMSEA (Root Mean Square Error of Approximation) = 0.062; CFI (Comparative Fit Index) =0.946; TLI (Tucker Lewis Index) =0.933; SRMR (Standardized Root Mean Square Residual) $=0.033$ ) and upper-secondary students (RMSEA $=0.066$; CFI $=0.941$; $\mathrm{TLI}=0.928$; SRMR $=0.036$ ). The scale has proven to be psychometrically appropriate on the sample of lower-secondary students (reliable: $0.702<\alpha>0.839$; sensitive: $r_{\text {average }}=0.600$; valid: $r A N U D-S T A I-X 2$ $=0.420$ ) and upper-secondary students (reliable: $0.717<\alpha>0.878$; sensitive: $r_{\text {average }}=0.600$ ).

\section{Results}

Table 1. Correlations between the 5Cs, general anxiety and anxiety components.

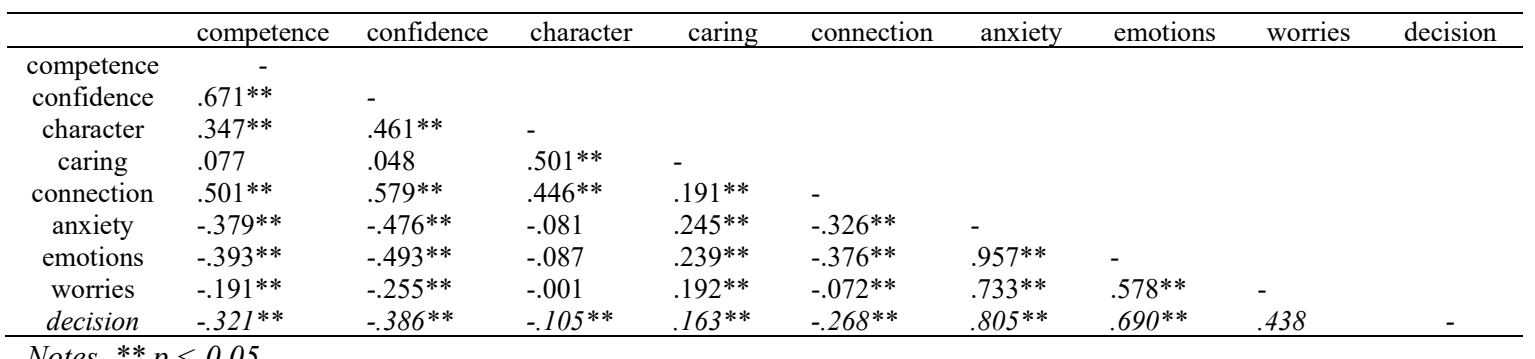

Notes. $* * p<0.05$

Table 1 shows a pattern of correlation coefficients between the 5Cs, general anxiety and its components. The highest coefficients can be found between general anxiety and confidence, followed by connection, while the coefficients are lower and mostly non-significant with character. Most of the coefficient between the $5 \mathrm{Cs}$ and anxiety are negative, with the exception of caring. 
Table 2. Predictive power of the 5Cs for general anxiety and components of anxiety.

\begin{tabular}{|c|c|c|c|c|c|}
\hline & $B(S E)$ & $\beta$ & $t$ & $\mathrm{R}^{2}$ & $\mathrm{R}^{2 *}$ \\
\hline \multicolumn{6}{|c|}{ Anxiety $(\mathrm{F}(5,394)=37.384, p=0.000)$} \\
\hline constant & $52.964(3.669)$ & & $14.435 * * *$ & & \\
\hline competence & $-0.275(0.157)$ & -0.101 & -1.758 & & \\
\hline confidence & $-0.892(0.170)$ & -0.342 & $-5.258 * * *$ & & \\
\hline character & $0.171(0.141)$ & 0.068 & 1.214 & & \\
\hline caring & $0.631(0.118)$ & 0.270 & $5.332^{* * *}$ & & \\
\hline connection & $-0.365(0.114)$ & -0.173 & $-3.193 * *$ & 0.322 & 0.313 \\
\hline \multicolumn{6}{|c|}{ Emotions $(\mathrm{F}(5,396)=42.299 ; p=.000)$} \\
\hline & $31.057(2.286)$ & & $13.589 * * *$ & & \\
\hline competence & $-0.154(0.098)$ & -0.089 & -1.581 & & \\
\hline confidence & $-0.574(0.105)$ & -0.346 & $-5.451 * * *$ & & \\
\hline character & $0.130(0.088)$ & 0.081 & 1.476 & & \\
\hline caring & $0.395(0.074)$ & 0.265 & $5.373 * * *$ & & \\
\hline connection & $-0.299(0.071)$ & -0.222 & $-4.195 * * *$ & 0.348 & 0.340 \\
\hline \multicolumn{6}{|c|}{ Worries $(\mathrm{F}(5,397)=10.009 ; p=.000)$} \\
\hline constant & $9.638(1.062)$ & & $9.074 * * *$ & & \\
\hline competence & $-0.052(0.045)$ & -0.075 & -1.155 & & \\
\hline confidence & $-0.151(0.049)$ & -0.228 & $-3.072 * *$ & & \\
\hline & $0.020(0.041)$ & 0.032 & 0.498 & & \\
\hline carring & $0.120(0.034)$ & 0.202 & $3.504^{* *}$ & & \\
\hline connection & $0.008(0.033)$ & 0.014 & 0.235 & 0.112 & 0.101 \\
\hline \multicolumn{6}{|c|}{ Decision $(\mathrm{F}(5,399)=18.989 ; p=.000)$} \\
\hline constant & $12.353(1.016)$ & & $12.153^{* * *}$ & & \\
\hline competence & $-0.068(0.044)$ & -0.097 & -1.566 & & \\
\hline confidence & $-0.164(0.047)$ & -0.247 & $-3.504 * *$ & & \\
\hline & $0.018(0.039)$ & 0.028 & 0.460 & & \\
\hline caring & $0.117(0.033)$ & 0.196 & $3.580 * * *$ & & \\
\hline connection & $-0.076(0.032)$ & -0.140 & $-2.394 * *$ & 0.192 & 0.182 \\
\hline
\end{tabular}

Notes. $* * p<0.05 ; * * * p<0.001$;

In Table 2, multiple linear regression for the components of anxiety is presented, with all 5Cs as predictors. Confidence is a negative predictor of general anxiety and all components of anxiety, while connection is a negative predictor of general anxiety and components emotion and decision. Caring is a significant positive predictor of general anxiety and all three components of anxiety. With included predictors, we can explain about $30 \%$ of the variance in general anxiety and its components, emotion. Variance explained was somewhat less for decision, about $18 \%$, and worries, about $10 \%$.

\section{Conclusions}

In the present paper, The PYD perspective (Lerner 2007) is used for the first time as a framework for an in-depth understanding of the 5Cs and anxiety among adolescents in Slovenia. Confidence and connection are significant predictors of anxiety and all its measured components in expected direction, indicating the important role that PYD can play in anxiety intervention and prevention within an educational framework. However, extra care would need to be taken when promoting caring. Our findings show positive associations between caring and anxiety and its components indicating that high levels of caring are related to high anxiety. Thus, future research can look into the question of what can be considered as optimal level of caring. 


\section{References}

Geldof, G. J., Bowers, E. P., Boyd, M. J., Mueller, M. K., Napolitano, C. M., Schmid, K. L., ... \& Lerner, R. M. (2013). Creation of short and very short measures of the five Cs of positive youth development. Journal of Research on Adolescence, 24, 163-176.

Gonzalez, J. M., Kozina, A., \& Wiium, N. (2017). Short-form measure of positive youth development: Psychometrics and preliminary findings in Slovenia. Paper presented at the European Congress of Developmental Psychology 2017, Utrecht, the Netherlands.

Ialongo, N., Edelsohn, G., Werthamer-Larsson, L., Crockett, L., \& Kellam, S. (1996). The course of aggression in first-grade children with and without co-morbid anxious symptoms. Journal of Abnormal Child Psychology, 24, 445-456.

Kozina, A, (2012). The LAOM Multidimensional Anxiety Scale for measuring anxiety in children and adolescents: Addressing the psychometric properties of the scale. Journal of Psychoeducational Assessment, 30, 264-273.

Kozina, A. (2014). Developmental and time-related trends of anxiety from childhood to early adolescence: two-wave cohort study. European Journal of Developmental Psychology, 11(5), 546-559.

Last, C.G., Hansen, C., \& Franco, N. (1997). Anxious children in adulthood: A prospective study of adjustment. Journal of the American Academy of Child and Adolescent Psychiatry, 36, 645-652.

Lerner, R. M. (2007). The good teen. New York: The Stonesong Press.

Lerner, R. M., Agans, J. P., Arbeit, M. R., Chase, P. A., Weiner, M. B., Schmid, K. L., \& Alberts Warren, A. E. (2013). Resilience and positive youth development: A relational Developmental Systems Model. In S. Goldstein \& R. B. Brooks, Handbook of resilience in children (pp. 293-308). New York: Springer.

Neil, A. L., \& Christensen, H. (2009). Efficacy and effectiveness of school-based prevention and early intervention programs for anxiety. Clinical Psychology Review, 29, 208-215.

Olatunji, B.O. \& Cole, D.A. (2009). The longitudinal structure of general and specific anxiety dimensions in children: Testing a latent trait-state-occasion model. Psychological Assessment, 21, 412-424.

Overton, W. F. (2015). Processes, relations, and relational-developmental-systems. In R. M. Lerner (Ed.), Handbook of Child Psychology and Developmental Science (pp. 1-54). Hoboken, USA: Wiley.

Schwartz, D.J., Hopmeyer, Gorman A., Nakamoto, \& McKay, T. (2006). Popularity, social acceptance, and aggression in adolescent peer groups: Links with academic performance and school attendance. Developmental Psychology, 42, 1116-1127.

Silverman, W. K., \& Treffers, P. D. A. (2001). Anxiety disorders in children and adolescents. Research, assessment and intervention. Cambridge, UK: Cambridge University Press.

Twenge, J. M. (2000). The age of anxiety? The birth cohort change in anxiety and neuroticism, 1952-1993. Journal of personality and social psychology, 79(6), 1007-1021.

Weems, C. F., \& Stickle, T. R. (2005). Anxiety disorders in childhood: Casting a nomological net. Clinical Child and Family Psychology Review, 8, 107-134.

Woodworth, L.J. \& Fergusson, D.M. (2001). Life course outcomes of young people with anxiety disorders in adolescence. Journal of the American Academy of Child and Adolescent Psychiatry, 40, 1086-1093. 